\title{
Prevention of Non-Cardiogenic Ischemic Stroke: Towards Personalized Stroke Care
}

\author{
Tihamer Molnar ${ }^{1}, \mathrm{MD}, \mathrm{PhD} \bullet$ Peter $\mathrm{Csecsei}^{2}, \mathrm{MD}, \mathrm{PhD}$ \\ ${ }^{1}$ Department of Anesthesiology and Intensive Care, University of Pecs, Medical School, \\ Pecs, Hungary; ${ }^{2}$ Department of Neurosurgery, University of Pecs, Medical School, \\ Pecs, Hungary.
}

Author for correspondence: Tihamer Molnar, Department of Anesthesiology and Intensive Care, University of Pecs, Ifjusag u. 13., Pecs, 7623 Hungary.

Email: tihamermolnar@yahoo.com

Doi: https://doi.org/10.36255/exonpublications.stroke.personalizedcare.2021

\begin{abstract}
Despite diagnostic advances and new evidence on how to best treat patients with ischemic stroke, the risk of stroke recurrence remains unacceptably high. Therefore, there is a great need for novel therapies and markers to guide risk stratification, reveal stroke aetiology, identify patients who may benefit most from interventions, predict risk for another stroke, and recognize the risk of short-term complications or unfavorable long-term outcomes. The purpose of this chapter is to provide an update on: (i) emerging markers in atherothrombotic stroke; (ii) role of systemic inflammation in contributing to stroke occurrence; (iii) the main antiplatelet agents that have been successfully used in the secondary prevention of non-cardiogenic ischemic stroke and transient ischemic attack; (iv) screening for high-on-treatment platelet reactivity after stroke; and (v) to explore novel and effective antiplatelet strategies for the secondary prevention of ischemic stroke. Rising questions such as indications for antiplatelet therapy after a successful recanalisation following acute ischemic stroke should be answered in the future to
\end{abstract}

In: Stroke. Dehkharghani S (Editor). Exon Publications, Brisbane, Australia. ISBN: 978-0-6450017-6-1; Doi: https://doi.org/10.36255/exonpublications.stroke.2021

Copyright: The Authors.

License: This open access article is licenced under Creative Commons Attribution-NonCommercial 4.0 International (CC BY-NC 4.0) https://creativecommons.org/licenses/by-nc/4.0/ 
optimize outcomes. Finally, we aim to focus on personalized antiplatelet regimens and current translational research findings in this field.

Keywords: antiplatelet therapy; cerebrovascular event; inflammation; ischemic stroke; personalized medicine

\section{INTRODUCTION}

Each year, over five million people die worldwide from stroke, (1). One out of four strokes is recurrent. Despite new evidence on how to best treat patients with ischemic stroke, the risk of stroke recurrence remains unacceptably high. Therefore, there is a great need for novel therapies and markers to: (i) guide risk stratification; (ii) reveal stroke aetiology; (iii) identify patients who may benefit most from interventions; (iv) predict risk for another stroke; and (v) recognise the risk of short-term complications or unfavourable long-term outcomes. In general, secondary stroke prevention starts with reduction of vascular risk factors such as obesity, hypertension, diabetes, dyslipidemia, and smoking (2). Strokes due to larger artery occlusion account for approximately a third of all ischemic strokes. In the case of symptomatic extracranial carotid stenosis, surgical intervention, either endarterectomy or stenting, as close as possible in time to the index event seems highly beneficial (2). With intracranial large artery atherosclerosis or lacunar stroke, the best medical therapy consists of antiplatelet medications, high-dose statins, aggressive control of vascular risk factors, and lifestyle modifications (2).

In this chapter, platelet-related factors including thrombo-inflammation and antiplatelet strategies are highlighted in non-cardiogenic ischemic stroke. Antiplatelets offer an absolute risk reduction of $2 \%$ in all vascular events per year, however, they increase the risk of major extracranial bleeding by $0.1-0.3 \%$ (3). Currently, aspirin is the only $1 \mathrm{~A}$ recommended antiplatelet agent in the secondary prevention of non-cardiogenic ischemic stroke according to an update of the 2018 Acute Ischemic Stroke Guideline of the American Heart Association and American Stroke Association (AHA/ASA) (4). Hence, all recently published studies analyzed the effectivness of aspirin alone or in combination with another agent including either clopidogrel, or ticagrelor as a dual antiplatelet therapy (DAPT) $(1,4)$. However, there is significant heterogenity among trials in terms of endpoints (stroke recurrence only or composite endpoints such as stroke, myocardial infarction, and mortality) as well as the length of follow-up. In general, antiplatelet monotherapy is usually favored over DAPT since DAPT is often associated with bleeding complications $(1,4)$. This leads to the issue of long-term safety and efficacy. While the guideline of AHA/ASA suggests aspirin monotherapy within 24 to 48 hours after an acute ischemic stroke, it suggests DAPT with aspirin and clopidogrel, starting within 24 hours of symptom onset, for 21 days in patients with minor stroke (1). Importantly, the efficacy of short-term DAPT to prevent recurrent ischemic stroke in patients with minor stroke or high-risk transient ischemic attack (TIA) was independently investigated in the CHANCE trial (Clopidogrel in High-Risk Patients with Acute Nondisabling Cerebrovascular Events) (5) and the POINT trial (Platelet-Oriented Inhibition in New TIA and Minor Ischaemic Stroke) (6). Both trials examined recurrence of cerebral ischemia and bleeding 
complications up to 90 days following the index event. The former reported a 32\% reduction in recurrent stroke without an increase in major bleeding and in the latter study DAPT was associated with a $28 \%$ reduction in ischemic stroke, but at the cost of more frequent bleeding. Importantly, the benefit from DAPT was even higher during the first 30 days of treatment, indicating that the risk of major stroke is extremely high immediately after a TIA or minor stroke for a few days (6).

Aspirin is recommended for secondary prevention after TIA or ischemic stroke on the basis of trials showing a 13\% reduction in long-term risk of recurrent stroke (7). The previously unrecognised effect of aspirin on the severity of early recurrent stroke, and the diminishing benefit with longer-term use was recently confirmed by a meta-analysis based on pooled data from 12 trials involving 15,778 participants (7). In patients receiving aspirin without a routine proton pump inhibitor (PPI) for secondary prevention, the long-term risk of major bleeding is higher, particularly in older patients, resulting in a substantial risk of disabling or fatal upper gastrointestinal bleeding (8). Given that half of the major bleeds in patients aged 75 years or older were upper gastrointestinal, the estimated number needed to treat (NNT) for routine PPI use to prevent such bleeds is low, and co-prescription should be encouraged (8).

There is no evidence that clopidogrel is superior to aspirin alone for secondary stroke prevention, but clopidogrel was significantly more effective than aspirin in the prevention of vascular events in patients with atherothrombotic disease manifested by recent myocardial infarction, recent ischemic stroke or symptomatic peripheral arterial occlusive disease in the CAPRIE study $(9,10)$. Despite similar tolerability profile of these drugs, the risk of gastrointestinal bleeding was significantly lower in clopidogrel recipients (11).

Several studies have shown improved results after open and endovascular coronary artery surgery, when patients had double and even triple antiplatelet therapy (12). Reasonably, these improved results have been attributed to the aggressive antiplatelet therapy with additional anti-inflammatory action. Conceptually, antiinflammatory drugs may beneficially alter the course of atherosclerosis, thus they can reduce the prevalence of cardiovascular events (13). Numerous physiopathological mechanisms characterize the atherosclerotic plaque development and progression providing several therapeutic targets. However, some reports have shown inadequate response to DAPT with aspirin and clopidogrel in 5-30\% of patients undergoing percutaneous coronary interventions (PCI), and this prevalence may increase up to $66 \%$ in patients undergoing neurointerventional procedures (14). The reason for such non-responsiveness can be multifactorial, due mostly to genetic (for example, polymorphisms on CYP2C19) and epigenetic (for example, platelet derived factors) alterations (15). Considering that the traditional concept of therapeutic regimens based on "one size fits all" does not work in preventing cardiovascular events, an individual approach in secondary stroke prevention is desired. We are witnesses to a paradigm shift in this field due to succesful implementation of numerous translational research findings into clinical practice.

\section{EMERGING MARKERS IN ATHEROTHROMBOTIC STROKE}

Considerable interest for cell-derived microparticles as disease markers has emerged, pointing out their role in hemostatic response. Besides, systemic 
inflammation-related factors leading to residual platelet reactivity have been highlighted recently. Based on the current trend, the assessment of systemic inflammatory parameters will play a pivotal role in decision-making regarding primary and secondary stroke prevention.

\section{Microvesicles}

In general, microvesicles (MVs), small extracellular plasma membrane particles shed by activated and apoptotic cells, have been linked to the development of cardiovascular diseases. MVs from vascular and resident cells, by facilitating exchange of biological information between neighboring cells, serve as mediators in the systemic circulation. Platelet-derived MVs (pMVs) via their procoagulant, pro-inflammatory and pro-atherosclerotic effects, play a pivotal role in the development and progression of atherosclerosis (16). These pMVs - the main source of total microparticles - promote the adhesion of platelets and leukocytes, especially monocytes, to endothelial cells at endothelial lesion sites via platelet/endothelial cell adhesion molecule (PECAM-1) and intercellular adhesive molecule-1 (ICAM-1) (17). Recently, the novel aspects of MV-mediated regulatory mechanisms including endothelial dysfunction (18), vascular wall inflammation (19), apoptosis (20) and their impact on the coagulation cascade (21) have been widely explored (22). Increased pMV formation was observed in TIA, acute ischemic stroke (IS) and convalescent stroke patients $(23,24)$. In addition, some pMV parameters in convalescent stroke subjects were found to be predictive for the next vascular event, despite decline in pMVs over time elapsed from stroke (25). High levels of circulating endothelial- and leukocyte-derived MVs after stroke were found to be associated with worse cardiovascular outcome within three years (26). Unfortunately, vascular disease-specific MVs precisely predicting the occurrence of either ischemic stroke or acute coronary syndrome have not been found so far. However, predominantly pMVs exhibiting thrombo-inflammatory properties contribute to progression of atherosclerosis and subsequent vascular complications (16).

\section{Screening for high-on-treatment platelet reactivity}

A recent meta-analysis reported data on the risk of ischemic stroke/TIA recurrence, indicating that patients with high-on-treatment platelet reactivity (HTPR) had a significantly higher risk for ischemic stroke/TIA recurrence $(\mathrm{RR}=1.81$, 95\% CI: 1.30-2.52; p < 0.001) (27). Based on platelet function testing, the prevalence of ex vivo HTPR in cardiovascular diseases varies between 3-62\% with aspirin monotherapy, 8-61\% with clopidogrel monotherapy and 56-59\% when dipyridamole is added to aspirin in the early, subacute or late phases after TIA/ stroke onset (28). In our own cohort, we combined the examination of endothelial and platelet-derived microvesicles and ex vivo platelet function in post-stroke patients taking clopidogrel. Both measurements were performed in whole blood and from the lower and upper blood fractions separated after 1-hour gravity sedimentation by the analogy with erythrocyte sedimentation rate (ESR) (29). We observed that the total MV number measured in the lower fraction after sedimentation showed a negative correlation with the area under the curve (AUC, 
reflecting the aggregation) value measured by Multiplate (Roche, Switzerland). When the values for each patient were dichotomized based on their HTPR status, a difference was found between clopidogrel responder and resistant cases. In clopidogrel non-responders, a positive correlation was found between the total MV number in the sedimented blood fraction and the AUC measured in whole blood. Similar association was recently found between antiplatelet potency of P2Y12 antagonists (prasugrel and ticagrelor) and decreased plasma CD42+/CD62P+ pMVs numbers (30). Although these observations are promising, a large, adequately-sized, prospective follow-up study should be conducted to explore the predictive value of this novel pMV-based approach in identification of patients at increased risk for vascular events. Although several studies show an increased rate of recurrent cerebrovascular ischemic events in patients presenting with HTPR, the diagnostics of HTPR remain unsolved $(27,31)$. Measurement of ex vivo platelet function in patients on antiplatelet therapy, using laboratory tests that correlate with their clinical effectiveness, would potentially enable physicians to tailor antiplatelet strategies to an individual. Importantly, a greater AUC ( $\geq 70$ as a cut-off value) from the separated upper blood sample after 1-hour gravity sedimentation emerged as a novel independent predictor of future stroke episodes, while the clopidogrel resistance state based on Multiplate electrode aggregometry from the whole blood was not able to predict recurrent stroke in a prospective study. Based on atomic force microscopy, the more reactive (greater AUC), ascending platelets were found to be larger in volume, suggesting a link between the function and size of platelets. In accordance, platelets with a higher mean volume showed association with high residual platelet reactivity after conventional dual antiplatelet therapy in patients with coronary artery disease (32). The ongoing release of MVs despite antiplatelet therapy might explain recurrent thrombotic events after acute myocardial infarction and worse clinical outcomes on clopidogrel compared to ticagrelor. Ticagrelor attenuates the increase of extracellular vesicle concentration in plasma after acute myocardial infarction compared to clopidogrel (33). This highlights the pleiotropic effect of ticagrelor attenuating the increase of concentration of MVs compared to clopidogrel $(30,33)$. However, similar findings are still lacking in patients after ischemic stroke. Ideally, the choice of antiplatelet agents should depend on patient-specific comorbidities, and the patient's access to health care. In the real world, aspirin, due to its low cost and extensive experience, is the leading choice of drug in most cases. Clopidogrel and aspirin with extendedrelease dipyridamole are reasonable alternatives as first-line therapy in those who have suffered a stroke, but the individually tailored dose and switch to other medication in the case of resistance requires more evidence.

\section{Systemic inflammation}

The extent of ischemic brain injury correlates with the magnitude of both local and systemic immune responses. In turn, inflammation is known to contribute to stroke occurrence (34). Therefore, the assessment of systemic inflammatory parameters carries additional clinical significance in primary and secondary stroke prevention. Observations on biomarker studies (35), and large-scale clinical trial support the operation of immune and inflammatory pathways in vascular diseases (36). An accurate review of the correlations between inflammation, 
infection, immunity and atherosclerosis was published by Libby et al. (37). Assessment of the thrombo-inflammatory cascade in the acute phase (38) and later in convalescent stroke patients are equally important (39). The association between infection and stroke is bidirectional. Although infection can lead to stroke, stroke per se induces immune suppression, increasing the risk of infection (39). An early activation of leukocytes indicated by an increase of leukocyte antisedimentation rate (LAR) was shown to be characteristic of acute ischemic cerebrovascular events $(40,41)$. The delayed and ameliorated LAR per se could differentiate TIA from definitive ischemic stroke (40). Deficient early activation of leukocytes predisposes to post-stroke infections, a considerable cause of poststroke morbidity (40). Trials with antibiotics have not reduced recurrent cardiovascular events, nor have vaccination strategies yet achieved clinical translation (42). Inflammatory biomarkers, such as C-reactive protein (CRP), measured with a highly sensitive assay (hsCRP), have been implemented into clinical practice, adding prognostic information on cardiovascular risk $(43,44)$. Based on JUPITER (Justification for the Use of Statins in Prevention: an Intervention Trial Evaluating Rosuvastatin) trial data, statins reduced the rate of first myocardial infarction, stroke, or confirmed cardiovascular death by $47 \%$ when given to patients with low-density lipoprotein-C levels of $<130 \mathrm{mg} / \mathrm{dl}$ and hsCRP of $>2 \mathrm{mg} / \mathrm{l}$ (hazard ratio: 0.53 ; 95\%CI: 0.40 to 0.69 ; p < 0.00001) (43). In current guidelines, hsCRP carries a class IIb assessment and is most appropriate in primary prevention when clinical decisions to initiate statin therapy are uncertain. Ongoing multinational trials are pursuing whether reducing inflammation will decrease vascular event rates. In secondary prevention, CANTOS allocated the anti-IL-1 antibody to stable post-ACS patients who had an hsCRP $>2 \mathrm{mg} / \mathrm{L}$ despite effective statin therapy (45). Those CANTOS participants who achieved a reduction of hsCRP to below $2 \mathrm{mg} / \mathrm{L}$ in response to the anti-inflammatory therapy had a greater than 30\% reduction in cardiovascular and in all-cause mortality (46). Besides CRP, another systemic inflammatory marker that has been extensively evaluated in the acute phase of ischemic stroke is interleukin-6 (IL-6). The proinflammatory cytokine IL- 6 was described as an early marker of brain damage caused by ischemic stroke $(47,48)$. In contrast to other pro-inflammatory cytokines (e.g. IL-1 beta, TNF-alpha and TNF-receptors), serum level of IL-6 showed a significant increase within the first hours following ischemic stroke and reached a plateau by day 3 and returned to baseline by day 7 , correlating with increasing volumes of lesion and poor functional outcome $(48,35)$. In addition, an altered physiological balance between pro-and anti-inflammatory molecules was observed in acute stroke patients, indicating a down-regulated anti-inflammatory response reflected by a lower level of interleukin-10 (49). Antagonism of such negative effects of IL-6 in ischemic stroke with antiplatelet agents showed conflicting results in patients with acute coronary events and ischemic stroke (50-52). However, there also appeared to be differences in the effect of each antiplatelet drug on IL-6, with ticagleror appearing to be more effective than clopidogrel in acute coronary events (53). Increased serum IL-6 per se is associated with higher risk of cardio- and cerebrovascular diseases. The circulating levels of IL-6 vary greatly between young individuals with moderate internal carotid artery stenosis (54). Recently, IL-6 G allele promoter emerged as a novel predictor for recurrence of stroke in the young (54). Besides, other inflammatory markers have also been associated with tissue damage due to acute ischemic stroke, such as IL-8, 
IL-9, CXCL-1 (55). Patients with radiologically confirmed cerebral infarctions had significantly elevated serum levels of CXCL-1 and IL-8 levels, and the latter correlated with age (55). In a recent prospective cohort study including 680 patients with ischemic stroke and TIA, IL-6, IL-8, and CRP independently predicted 1-year recurrent vascular events including ischemic stroke (56). Both IL-6 and CRP independently predicted 1-year mortality and poor functional outcome (56). A clear increase in inflammatory markers in the early stage of ischemic stroke suggests that therapy to high-risk patients with hyperinflammatory state may be beneficial. Accordingly, drugs that simultaneously decrease platelet function and inflammation may improve the treatment of cardiovascular disorders. In a platelet-monocyte inflammatory model system, dipyridamole exhibited selective anti-inflammatory action, inhibiting inflammatory gene expression in platelet-monocyte aggregates that may contribute to its effectiveness in the secondary stroke prevention (57).

The tumor necrosis factor (TNF) superfamily (TNFSF) are proteins which are expressed predominantly by immune cells and regulate diverse cell functions, including immune response and inflammation. These molecules can also stimulate and inhibit certain immunological processes, depending on the receptor they act on (58). The superfamily contains 19 members that bind to 29 members of TNF receptor superfamily (59). OX40 ligand (OX40L/TNFSF4) has been studied in 294 patients with ischemic stroke and it was found that serum OX40L levels were significantly higher in patients with severe cerebral infarction compared to healthy controls, and were significantly higher in nonsurvivors compared to survivors. A multivariate logistic regression analysis also showed that serum OX40L level was an independent prognostic factor for 60-day mortality (60). TNF-related apoptosis-inducing ligand (TRAIL/TNFSF10) showed significant negative correlations with NIHSS score and stroke volume independently from stroke subtypes, suggesting that serum TRAIL might also have a role in acute ischemic stroke (61). Tumor necrosis factor-like weak inducer of apoptosis (TWEAK/TNFSF12) is also involved in the inflammatory process during ischemic stroke. TWEAK and its membrane receptor Fnl4 are upregulated in infarcted brain tissue, suggesting its role in stroke outcome (62). The role of inflammatory markers in the severity and outcome of stroke is crucial, and these examples illustrate the potential of guiding therapy according to inflammatory status assessed by biomarkers in trials and clinical practice.

\section{Inflammatory status as a predictor of recurrent non-cardiogenic ischemic stroke}

In the real world, simple laboratory tests such as the count of peripheral blood cell components in the hyperacute stage of ischemic stroke also provide significant information on risk of complications and outcome. According to a systematic review, an elevated neutrophil-to-lymphocyte ratio (NLR) correlated with poor functional outcome and increased chance of developing symptomatic intracranial hemorrhage (63). During stroke reperfusion therapy, NLR predicted cerebral edema and clinical worsening at an early stage (64). According to another recent review, novel peripheral blood cell ratios such as platelet-to-neutrophil ratio (PNR), platelet-to-white blood cell ratio (PWR) and NLR were associated with a 90-day mortality of patients with AIS (65). Patients with high NLRs or low PWRs 
and PNRs may have a greater risk of mortality than other patients (65). Expansion of circulating CD4+CD28- T-cell subset was found to be associated with an increasing risk of stroke recurrence and death (66).

In a study of people without known cardiovascular disease, the The Emerging Risk Factors Collaboration concluded that assessment of the CRP or fibrinogen level in people at intermediate risk for a cardiovascular event could help prevent one additional event over a period of 10 years for every 400 to 500 people screened (67). Studies suggest a cumulative effect of LDL cholesterol and CRP on recurrent stroke and TIA in patients with ischemic stroke, recommending evaluation of both LDL cholesterol and CRP for better medical management with statin in patients with a history of ischemic stroke (68). A prospective cohort study demonstrated an association between higher levels of IL-6, CRP and fibrinogen, but not leukocytes, and an increased incidence of occlusive vascular events in patients after stroke (69). Others found a pivotal role of activated leukocytes (partcularly neutrophils) and platelets (partcularly reticulated) in thrombus formation (70). As a vicious circle, atherosclerosis reduces platelet survival and thereby increases the percentage of younger reticulated platelets in the circulation, thus having a greater propensity for thrombus participation under shear conditions of coronary artery stenosis (71). In accordance, elevated circulating reticulated platelets, as a marker of increased platelet production/turnover were observed following an ischemic event in a TIA/ischemic stroke population (71). In a cheap and simple laboratory setting, the motion of peripheral blood cells (leukocytes, neutrophils, platelets etc.) were examined during 1-hour gravity sedimentation by the analogy of ESR. An upward motion (called antisedimentation) of both leukocytes and platelets proportional to their activation was described previously in acute ischemic stroke (40), post-stroke infection (41) and burn patients (72). In contrast, a downward motion of neutrophils during 1-hour gravity sedimentation expressed by a negative value of neutrophil antisedimentation rate was observed in those patients who suffered from composite vascular events during 36-month follow-up. In contrast, neither leukocyte antisedimentation rate nor platelet antisedimentation rate was found to be predictive for future vascular events reflecting the role of leukocytes and platelets predominantly in the acute phase of stroke. In accordance with others, our finding also suggests that neutrophils are important markers of stroke outcome (73) as their predictive role has recently been shown in patients with acute coronary syndrome (74). Besides hsCRP, procalcitonin (PCT) - a prohormone of calcitonin, produced by C-cells of the thyroid gland-emerged as an independent prognostic marker of 1-year functional outcome and death (odds ratio (OR) 2.33 (95\% CI, 1.33-3.44) and 3.11 (2.02-4.43), respectively, $\mathrm{P}<0.0001$ for both, adjusted for age, NIHSS, other predictors, and vascular risk factors) in patients with AIS (75). In the Northern Manhattan Study (NOMAS) cohort, the associations of PCT and midregional proatrial natriuretic peptide (MRproANP) with ischemic stroke risk differed by stroke etiology. PCT levels in the top quartile were particularly associated with small vessel stroke (adjusted HR, 5.1; 95\% CI, 1.4-18.7) and MRproANP levels with cardioembolic stroke (adjusted HR, 16.3; 95\% CI, 3.7-70.9) (76). In an intention-to-treat-analysis, the PCT-guided antibiotic therapy did not improve functional outcome at three months after severe ischemic stroke, while a post hoc analysis demonstrated a significant increase on the first day of infection in patients 
with pneumonia and sepsis compared to patients with urinary tract infections or without infections (77).

\section{PERSPECTIVES}

Careful assessment of risks for infection are needed in anti-inflammatory trials. The measurement of inflammatory biomarkers should be combined with the use of imaging biomarkers. Several promising attempts using novel modalities should be mentioned. For example: (i) borderzone infarcts and impaired collateral flow were able to identify a subgroup of patients with intracranial stenosis who were at particularly high risk of recurrent stroke on medical treatment (78); (ii) the Stroke Imaging Package Study of Intracranial Atherosclerosis (SIPS-ICAS) study group provided novel insights into the pathophysiology of intracranial atherosclerosis and identified specific imaging markers for risk stratification and prognosis prediction by high-resolution magnetic resonance imaging (79); and (iii) considering the overlap between subjects with cardio- and cerebrovascular pathology, a special combination of a pharmacological stressor (dipyridamole) and post-stress/rest neuroimaging along with assessment of certain systemic markers were used in more precise identification of patients at risk for a shared coronary and cerebral ischemia (80). In another innovative study, enhanced platelet production (higher platelet count), secretion (increased CD62P and CD63 expression) and activation (more neutrophil-platelet and monocyte-platelet complexes) were observed in recently symptomatic ( $\leq 4$ weeks of TIA or ischaemic stroke) carotid stenosis patients with 'Grey-Scale Median echodense plaques' compared with their asymptomatic counterparts, suggesting that simultaneous assessment of neurovascular imaging and platelet biomarkers may aid risk-stratification in carotid stenosis (81).

\section{CONCLUSION}

Large, adequately-sized, prospective multicentre studies are needed to determine whether assessment of HTPR at high and low shear stress with a range of userfriendly platelet function testing platforms, in conjunction with pharmacogenetic data, will improve our ability to predict the risk of recurrent vascular events in patients with different stage of atherosclerosis, providing a chance to enhance secondary prevention following TIA or ischaemic stroke $(27,82)$. The principle that each patient should be considered as an individual in choosing the most appropriate treatment remains a cornerstone for an optimal treatment to achieve a better clinical outcome. In this context, medical therapy, both for primary and secondary prevention, as well as in the acute phase of a cardiovascular event, should be chosen, also taking into consideration inflammatory parameters. With increased understanding of the specific mechanisms that regulate the relationship between thrombo-inflammation and atherosclerosis, new, more effective and specific anti-inflammatory treatment may become available. However, approximately 
one-third of patients are estimated to be nonadherent to secondary prevention medications (83). Persistence with antiplatelet medication within a cohort of hospitalized ischemic stroke patients was associated with a $72.5 \%$ lower likelihood of recurrent hospitalized stroke (84). This is likely to be helped by a better interpersonal communication between professionals and the lay population in the future.

Conflict of interest: The authors declare no potential conflict of interest with respect to research, authorship and/or publication of this chapter.

Copyright and permission statement: The authors confirm that the materials included in this chapter do not violate copyright laws. Where relevant, appropriate permissions have been obtained from the original copyright holder(s), and all original sources have been appropriately acknowledged or referenced.

\section{REFERENCES}

1. Hankey GJ, Warlow CP. Treatment and secondary prevention of stroke: evidence, costs, and effects on individuals and populations. Lancet. 1999;354(9188):1457-63. https://doi.org/10.1016/ S0140-6736(99)04407-4

2. Esenwa C, Gutierrez J. Secondary stroke prevention: challenges and solutions. Vasc Health Risk Manag. 2015;11:437-50. https://doi.org/10.2147/VHRM.S63791

3. Baigent C, Blackwell L, Collins R, Emberson J, Godwin J, Peto R, et al. Aspirin in the primary and secondary prevention of vascular disease: collaborative meta-analysis of individual participant data from randomised trials. Lancet.373(9678):1849-60. https://doi.org/10.1016/S0140-6736(09)60503-1

4. Powers WJ, Rabinstein AA, Ackerson T, Adeoye OM, Bambakidis NC, Becker K, et al. Guidelines for the Early Management of Patients With Acute Ischemic Stroke: 2019 Update to the 2018 Guidelines for the Early Management of Acute Ischemic Stroke: A Guideline for Healthcare Professionals From the American Heart Association/American Stroke Association. Stroke. 2019;50(12):e344-e418. https://doi.org/10.1161/STR.0000000000000211

5. Wang Y, Wang Y, Zhao X, Liu L, Wang D, Wang C, et al. CHANCE Investigators. Clopidogrel with aspirin in acute minor stroke or transient ischemic attack. N Engl J Med. 2013;369(1):11-9. https:// doi.org/10.1056/NEJMoal215340

6. Johnston SC, Easton JD, Farrant M, Barsan W, Conwit RA, Elm JJ, et al. Clinical Research Collaboration, Neurological Emergencies Treatment Trials Network, and the POINT Investigators. Clopidogrel and Aspirin in Acute Ischemic Stroke and High-Risk TIA. N Engl J Med. 2018;379(3):215-25. https://doi. org/10.1056/NEJMoal800410

7. Rothwell PM, Algra A, Chen Z, Diener HC, Norrving B, Mehta Z. Effects of aspirin on risk and severity of early recurrent stroke after transient ischaemic attack and ischaemic stroke: timecourse analysis of randomised trials. Lancet. 2016;388(10042):365-75. https://doi.org/10.1016/ S0140-6736(16)30468-8

8. Li L, Geraghty OC, Mehta Z, Rothwell PM. Oxford Vascular Study. Age-specific risks, severity, time course, and outcome of bleeding on long-term antiplatelet treatment after vascular events: a population-based cohort study. Lancet. 2017;390(10093):490-9. https://doi.org/10.1016/ S0140-6736(17)30770-5

9. Gent M, Beaumont D, Blanchard J, Bousser MG, Coffman J, Easton JD, et al. A randomised, blinded, trial of clopidogrel versus aspirin in patients at risk of ischaemic events (CAPRIE). CAPRIE Steering Committee. Lancet. 1996;348(9038):1329-39. https://doi.org/10.1016/S0140-6736(96)09457-3

10. Harker LA, Boissel JP, Pilgrim AJ, Gent M. Comparative safety and tolerability of clopidogrel and aspirin: results from CAPRIE. CAPRIE Steering Committee and Investigators. Clopidogrel versus aspirin in patients at risk of ischaemic events. Drug Saf. 1999;21(4):325-35. https://doi. org/10.2165/00002018-199921040-00007 
11. Jarvis B, Simpson K. Clopidogrel: a review of its use in the prevention of atherothrombosis. Drugs. 2000;60(2):347-77. https://doi.org/10.2165/00003495-200060020-00012

12. Peterson BE, Bhatt DL. Management of Anticoagulation in Patients with Atrial Fibrillation Undergoing PCI: Double or Triple Therapy? Curr Cardiol Rep. 2018;20(11):110. https://doi.org/10.1007/ sl1886-018-1045-0

13. Sterpetti AV. Inflammatory Cytokines and Atherosclerotic Plaque Progression. Therapeutic Implications. Curr Atheroscler Rep. 2020;22(12):75. https://doi.org/10.1007/s11883-020-00891-3

14. Duconge J, Hernandez-Suarez DF. Potential Usefulness of Clopidogrel Pharmacogenetics in Cerebral Endovascular Procedures and Carotid Artery Stenting. Curr Clin Pharmacol. 2017;12(1):11-7. https://doi.org/10.2174/1574884712666170227154654

15. Lukasik M, Rozalski M, Luzak B, Michalak M, Ambrosius W, Watala C, et al. Enhanced plateletderived microparticle formation is associated with carotid atherosclerosis in convalescent stroke patients, Platelets 2013;24(1):63-70. https://doi.org/10.3109/09537104.2011.654292

16. Badimon L, Suades R, Arderiu G, Pena E, Chiva-Blanch G, Padro T. Microvesicles in atherosclerosis and angiogenesis: from bench to bedside and reverse, Front Cardiovasc Med. 2017;4:77. https://doi. org/10.3389/fcrm.2017.00077

17. Rautou PE, Leroyer AS, Ramkhelawon B, Devue C, Duflaut D, Vion AC, et al. Microparticles from human atherosclerotic plaques promote endothelial ICAM-1- dependent monocyte adhesion and transendothelial migration. Circ. Res. 2011;108(3):335-43. https://doi.org/10.1161/ CIRCRESAHA. 110.237420

18. Lin ZB, Ci HB, Li Y, Cheng TP, Liu DH, Wang YS, Xu J, et al. Endothelial microparticles are increased in congenital heart diseases and contribute to endothelial dysfunction. J Transl Med. 2017;15(1):4. https://doi.org/10.1186/s12967-016-1087-2

19. Barry OP, Praticò D, Savani RC, FitzGerald GA. Modulation of monocyte-endothelial cell interactions by platelet microparticles. J Clin Invest. 1998;102(1):136-44. https://doi.org/10.1172/JCI2592

20. Niessen A, Heyder P, Krienke S, Blank N, Tykocinski LO, Lorenz HM, et al. Apoptotic-cell-derived membrane microparticles and IFN- $\alpha$ induce an inflammatory immune response. J Cell Sci. 2015;128(14):2443-53. https://doi.org/10.1242/jcs.162735

21. Mallat Z, Hugel B, Ohan J, Lesèche G, Freyssinet JM, Tedgui A. Shed membrane microparticles with procoagulant potential in human atherosclerotic plaques: a role for apoptosis in plaque thrombogenicity. Circulation. 1999;99(3):348-53. https://doi.org/10.1161/01.CIR.99.3.348

22. Burnier L, Fontana P, Kwak BR, Angelillo-Scherrer A. Cell-derived microparticles in haemostasis and vascular medicine. Thromb Haemost. 2009;101(3):439-51. https://doi.org/10.1160/TH08-08-0521

23. Cherian P, Hankey GJ, Eikelboom JW, Thom J, Baker RI, McQuillan A, et al. Endothelial and platelet activation in acute ischemic stroke and its etiological subtypes. Stroke. 2003;34(9):2132-7. https:// doi.org/10.1161/01.STR.0000086466.32421.F4

24. Lukasik M, Rozalski B, Luzak M, Michalak W, Ambrosius C, Watala, et al. Enhanced platelet-derived microparticle formation is associated with carotid atherosclerosis in convalescent stroke patients. Platelets. 2013;24(1):63-70. https://doi.org/10.3109/09537104.2011.654292

25. Rosińska J, Ambrosius W, Maciejewska J, Narożny R, Kozubski W, Łukasik M. Association of platelet-derived microvesicles and their phenotypes with carotid atherosclerosis and recurrent vascular events in patients after ischemic stroke. Thromb Res. 2019;176:18-26. https://doi.org/10.1016/j. thromres.2019.01.014

26. Huo S, Kränkel N, Nave AH, Sperber PS, Rohmann JL, Piper SK, et al. Endothelial and leukocyte-derived microvesicles and cardiovascular risk after stroke-PROSCIS-B. Neurology. 2021;96(6):e937-e946.

27. Fiolaki A, Katsanos AH, Kyritsis AP, Papadaki S, Kosmidou M, Moschonas IC, et al. High on treatment platelet reactivity to aspirin and clopidogrel in ischemic stroke: A systematic review and metaanalysis. J Neurol Sci. 2017;376:112-16. https://doi.org/10.1016/j.jns.2017.03.010

28. Lim ST, Coughlan CA, Murphy SJ, Fernandez-Cadenas I, Montaner J, Thijs V, et al. Platelet function testing in transient ischaemic attack and ischaemic stroke: A comprehensive systematic review of the literature. Platelets. 2015;26(5):402-12. https://doi.org/10.3109/09537104.2015.1049139

29. Ezer E, Schrick D, Tőkés-Füzesi M, Szapary L, Bogar L, Molnar T. A novel approach of platelet function test for prediction of attenuated response to clopidogrel. Clin Hemorheol Microcirc. 2019;73(2):359-69. https://doi.org/10.3233/CH-190580 
30. Chyrchel B, Drożdż A, Długosz D, Stępień EŁ, Surdacki A. Platelet Reactivity And Circulating PlateletDerived Microvesicles Are Differently Affected By P2Y(12) Receptor Antagonists. Int J Med Sci. 2019;16(2):264-75. https://doi.org/10.7150/ijms.28580

31. Yan AR, Naunton M, Peterson GM, Fernandez-Cadenas I, Mortazavi R. Effectiveness of Platelet Function Analysis-Guided Aspirin and/or Clopidogrel Therapy in Preventing Secondary Stroke: A Systematic Review and Meta-Analysis. J Clin Med. 2020;9(12):3907. https://doi.org/10.3390/ jcm9123907

32. Kim YG, Suh JW, Yoon CH, Oh IY, Cho YS, Youn TJ, et al. Platelet volume indices are associated with high residual platelet reactivity after antiplatelet therapy in patients undergoing percutaneous coronary intervention. J Atheroscler Thromb. 2014;21(5):445-53. https://doi.org/10.5551/jat.20156

33. Gasecka A, Nieuwland R, Budnik M, Dignat-George F, Eyileten C, Harrison P, et al. Ticagrelor attenuates the increase of extracellular vesicle concentrations in plasma after acute myocardial infarction compared to clopidogrel. J Thromb Haemost. 2020;18(3):609-23. https://doi.org/10.1111/jth.14689

34. Hankey GJ. Stroke. Lancet. 2017;389(10069):641-54. https://doi.org/10.1016/S0140-6736 (16)30962-X

35. Pusch G, Debrabant B, Molnar T, Feher G, Papp V, Banati M, et al. Early Dynamics of P-selectin and Interleukin 6 Predicts Outcomes in Ischemic Stroke. J Stroke Cerebrovasc Dis. 2015;24(8):1938-47. https://doi.org/10.1016/j.jstrokecerebrovasdis.2015.05.005

36. Taleb S. Inflammation in atherosclerosis. Arch Cardiovasc Dis. 2016;109(12):708-15. https://doi. org/10.1016/j.acvd.2016.04.002

37. Libby P, Loscalzo J, Ridker PM, Farkouh ME, Hsue PY, Fuster V, et al. Inflammation, immunity, and infection in atherothrombosis: JACC review topic of the week. J Am Coll Cardiol. 2018;72(17): 2071-81. https://doi.org/10.1016/j.jacc.2018.08.1043

38. Csecsei P, Pusch G, Ezer E, Berki T, Szapary L, Illes Z, et al. Relationship between Cardiac Troponin and Thrombo-Inflammatory Molecules in Prediction of Outcome after Acute Ischemic Stroke. J Stroke Cerebrovasc Dis. 2018;27(4):951-6. https://doi.org/10.1016/j.jstrokecerebrovasdis.2017.10.040

39. Elkind MSV, Boehme AK, Smith CJ, Meisel A, Buckwalter MS. Infection as a Stroke Risk Factor and Determinant of Outcome After Stroke. Stroke. 2020;51(10):3156-68. https://doi.org/10.1161/ STROKEAHA. 120.030429

40. Molnar T, Peterfalvi A, Szereday L, Pusch G, Szapary L, Komoly S, et al. Deficient leukocyte antisedimentation is related to post-stroke infections and outcome. J Clin Pathol. 2008;61(11):1209-13. https://doi.org/10.1136/jcp.2008.059840

41. Molnar T, Papp V, Banati M, Szereday L, Pusch G, Szapary L, et al. Relationship between C-reactive protein and early activation of leukocytes indicated by leukocyte antisedimentation rate (LAR) in patients with acute cerebrovascular events. Clin Hemorheol Microcirc. 2010;44(3):183-92. https:// doi.org/10.3233/CH-2010-1273

42. Shah PK, Chyu KY, Dimayuga PC, Nilsson J. Vaccine for atherosclerosis. J Am Coll Cardiol. 2014;64(25):2779-91. https://doi.org/10.1016/j.jacc.2014.10.018

43. Ridker PM, Danielson E, Fonseca FA, Genest J, Gotto AM Jr, Kastelein JJ et al. Rosuvastatin to Prevent Vascular Events in Men and Women with Elevated C-Reactive Protein. N Engl J Med. 2008;359(21):2195-207. https://doi.org/10.1056/NEJMoa0807646

44. Ridker PM. A Test in Context: High-Sensitivity C-Reactive Protein. J Am Coll Cardiol. 2016;67(6): 712-23. https://doi.org/10.1016/j.jacc.2015.11.037

45. Ridker PM, Thuren T, Zalewski A, Libby P. Interleukin-1 $\beta$ inhibition and the prevention of recurrent cardiovascular events: rationale and design of the Canakinumab Anti-inflammatory Thrombosis Outcomes Study (CANTOS). Am Heart J. 2011;162(4):597-605. https://doi.org/10.1016/j. ahj.2011.06.012

46. Ridker PM, MacFadyen JG, Everett BM, Libby P, Thuren T, Glynn RJ, CANTOS Trial Group. Relationship of C-reactive protein reduction to cardiovascular event reduction following treatment with canakinumab: a secondary analysis from the CANTOS randomised controlled trial. Lancet. 2018 Jan 27;391(10118):319-28.

47. Tarkowski E, Rosengren L, Blomstrand C, Wikkelsö C, Jensen C, Ekholm S, et al. Early intrathecal production of interleukin-6 predicts the size of brain lesion in stroke. Stroke. 1995;26(8):1393-8. https://doi.org/10.1161/01.STR.26.8.1393 
48. Fassbender K, Rossol S, Kammer T, Daffertshofer M, Wirth S, Dollman M, et al. Proinflammatory cytokines in serum of patients with acute cerebral ischemia: kinetics of secretion and relation to the extent of brain damage and outcome of disease. J Neurol Sci. 1994;122(2):135-9. https://doi. org/10.1016/0022-510X(94)90289-5

49. Perini F, Morra M, Alecci M, Galloni E, Marchi M, Toso V. Temporal profile of serum anti-inflammatory and pro-inflammatory interleukins in acute ischemic stroke patients. Neurol Sci. 2001;22(4):289-96. https://doi.org/10.1007/s10072-001-8170-y

50. Yang B, Zheng C, Yu H, Zhang R, Li S, Len M, et al. Comparison of Efficacy between Clopidogrel and Ticagrelor in Patients with Acute Coronary Syndrome after Interventional Treatment and Their Effects on IL-6. Iran J Public Health. 2020;49(2):240-48. https://doi.org/10.18502/ijph.v49i2.3086

51. Husted S, Storey RF, Harrington RA, Emanuelsson H, Cannon CP. Changes in inflammatory biomarkers in patients treated with ticagrelor or clopidogrel. Clin Cardiol. 2010;33(4):206-12. https://doi. org/10.1002/clc.20732

52. Sternberg Z, Chichelli T, Sternberg D, Sawyer R, Ching M, Janicke D, et al. Relationship between Inflammation and Aspirin and Clopidogrel Antiplatelet Responses in Acute Ischemic Stroke. J Stroke Cerebrovasc Dis. 2016;25(2):327-34. https://doi.org/10.1016/j. jstrokecerebrovasdis.2015.10.001

53. Thomas MR, James SK, Becker RC, Himmelmann A, Katus HA, Cannon CP, et al. Prognostic impact of baseline inflammatory markers in patients with acute coronary syndromes treated with ticagrelor and clopidogrel. Eur Heart J Acute Cardiovasc Care. 2019:2048872619878075. https://doi. org/10.1177/2048872619878075

54. Ou M, Liu S, Ma X, Xing X, He W, Gao H. IL-6 promoter polymorphism increased risks of recurrent stroke in the young patients with moderate internal carotid artery stenosis. J Cell Biochem. 2018;119(3):2886-90. https://doi.org/10.1002/jcb.26467

55. Ormstad H, Aass HC, Lund-Sørensen N, Amthor KF, Sandvik L. Serum levels of cytokines and C-reactive protein in acute ischemic stroke patients, and their relationship to stroke lateralization, type, and infarct volume. J Neurol. 2011;258(4):677-85. https://doi.org/10.1007/s00415-011-6006-0

56. Coveney SA, Murphy S, Belton O, Cassidy T, Crowe M, Dolan E, et al. Inflammatory cytokines, high sensitivity CRP, and risk of 1-year vascular events, death and poor functional outcome after stroke and TIA. Int J Stroke. 2021;1747493021995595. https://doi.org/10.1177/1747493021995595

57. Weyrich AS, Denis MM, Kuhlmann-Eyre JR, Spencer ED, Dixon DA, Marathe GK, et al. Dipyridamole selectively inhibits inflammatory gene expression in platelet-monocyte aggregates. Circulation. 2005;111(5):633-42. https://doi.org/10.1161/01.CIR.0000154607.90506.45

58. Ward-Kavanagh LK, Lin WW, Šedý JR, Ware CF. The TNF Receptor Superfamily in Co-stimulating and Co-inhibitory Responses. Immunity. 2016;44(5):1005-19. https://doi.org/10.1016/j.immuni. 2016.04.019

59. Aggarwal BB, Gupta SC, Kim JH. Historical perspectives on tumor necrosis factor and its superfamily: 25 years later, a golden journey. Blood. 2012;119(3):651-65. https://doi.org/10.1182/ blood-2011-04-325225

60. Mao LL, Chen WY, Ma AJ, Ji LL, Huang TT. High serum OX40 ligand correlates with severity and mortality in patients with massive cerebral infarction. Medicine (Baltimore). 2020;99(29):e20883. https://doi.org/10.1097/MD.0000000000020883

61. Kang YH, Park MG, Noh KH, Park HR, Lee HW, Son SM, et al. Low serum TNF-related apoptosisinducing ligand (TRAIL) levels are associated with acute ischemic stroke severity. Atherosclerosis. 2015;240(1):228-33. https://doi.org/10.1016/j.atherosclerosis.2015.03.028

62. Inta I, Frauenknecht K, Dörr H, Kohlhof P, Rabsilber T, Auffarth GU, et al. Induction of the cytokine TWEAK and its receptor Fnl4 in ischemic stroke. J Neurol Sci. 2008;275(1-2):117-20. https://doi. org/10.1016/j.jns.2008.08.005

63. Paudel SS, Thapa B, Luitel R. Neutrophil Lymphocyte Ratio as a Prognostic Marker in Acute Ischemic Stroke: a Systematic Review and Meta-analysis. J Nepal Health Res Counc. 2021;18(4):573-79. https://doi.org/10.33314/jnhrc.v18i4.3143

64. Ferro D, Matias M, Neto J, Dias R, Moreira G, Petersen N, et al. Neutrophil-to-Lymphocyte Ratio Predicts Cerebral Edema and Clinical Worsening Early After Reperfusion Therapy in Stroke. Stroke. 2021:STROKEAHA120032130. https://doi.org/10.1161/STROKEAHA.120.032130 
65. Cao X, Zhu Q, Xia X, Yao B, Liang S, Chen Z, et al. The correlation between novel peripheral blood cell ratios and 90-day mortality in patients with acute ischemic stroke. PLoS One. 2020;15(8):e0238312. https://doi.org/10.1371/journal.pone.0238312

66. Nadareishvili ZG, Li H, Wright V, Maric D, Warach S, Hallenbeck JM, et al. Elevated pro-inflammatory CD4+CD28- lymphocytes and stroke recurrence and death. Neurology. 2004;63(8):1446-51. https:// doi.org/10.1212/01.WNL.0000142260.61443.7C

67. Emerging Risk Factors Collaboration. C-reactive protein, fibrinogen, and cardiovascular disease prediction. N Engl J Med. 2012;367(14):1310-20. https://doi.org/10.1056/NEJMoa1107477

68. Kitagawa K, Hosomi N, Nagai Y, Kagimura T, Ohtsuki T, Maruyama H, et al. J-STARS collaborators. Cumulative Effects of LDL Cholesterol and CRP Levels on Recurrent Stroke and TIA. J Atheroscler Thromb. 2019;26(5):432-41. https://doi.org/10.5551/jat.45989

69. Whiteley W, Jackson C, Lewis S, Lowe G, Rumley A, Sandercock P, et al. Association of circulating inflammatory markers with recurrent vascular events after stroke: a prospective cohort study. Stroke. 2011;42(1):10-6. https://doi.org/10.1161/STROKEAHA.110.588954

70. Mc Bane RD, Gonzales C, Hodge DO, Wysokinski WE. Propensity for young reticulated platelet recruitment into arterial thrombi. J Thromb Thrombolysis. 2014;37(2):148-54. https://doi. org/10.1007/s1 1239-013-0932-x

71. Lim ST, Tobin WO, Murphy S, Kinsella JA, Smith DR, Lim SY, et al. Profile of reticulated platelets in the early, subacute and late phases after transient ischemic attack or ischemic stroke. Platelets. 2020:1-9. https://doi.org/10.1080/09537104.2020.1850670

72. Loibl C, Rozanovic M, Bogár L, Pankaczi A, Kovács P, Miseta A, et al. Lack of early platelet and leukocyte activation can indicate complications after major burn injury. Clin Hemorheol Microcirc. 2021;77(1):17-26. https://doi.org/10.3233/CH-190779

73. Ruhnau J, Schulze J, Dressel A, Vogelgesang A. Thrombosis, Neuroinflammation, and Poststroke Infection: The Multifaceted Role of Neutrophils in Stroke. J Immunol Res. 2017;2017:5140679. https://doi.org/10.1155/2017/5140679

74. Dong CH, Wang ZM, Chen SY. Neutrophil to lymphocyte ratio predict mortality and major adverse cardiac events in acute coronary syndrome: A systematic review and meta-analysis. Clin Biochem. 2018;52:131-136. https://doi.org/10.1016/j.clinbiochem.2017.11.008

75. Wang C, Gao L, Zhang ZG, Li YQ, Yang YL, Chang T, et al. Procalcitonin Is a Stronger Predictor of LongTerm Functional Outcome and Mortality than High-Sensitivity C-Reactive Protein in Patients with Ischemic Stroke. Mol Neurobiol. 2016;53(3):1509-17. https://doi.org/10.1007/s12035-015-9112-7

76. Katan M, Moon YP, Paik MC, Mueller B, Huber A, Sacco RL, et al. Procalcitonin and midregional proatrial natriuretic peptide as markers of ischemic stroke: the northern Manhattan study. Stroke. 2016;47(7):1714-19. https://doi.org/10.1161/STROKEAHA.115.011392

77. Ulm L, Hoffmann S, Nabavi D, Hermans M, Mackert BM, Hamilton F, et al. The Randomized Controlled STRAWINSKI Trial: Procalcitonin-Guided Antibiotic Therapy after Stroke. Front Neurol. 2017;8:153. https://doi.org/10.3389/fneur.2017.00153

78. Wabnitz AM, Derdeyn CP, Fiorella DJ, Lynn MJ, Cotsonis GA, Liebeskind DS, et al. SAMMPRIS Investigators. Hemodynamic Markers in the Anterior Circulation as Predictors of Recurrent Stroke in Patients With Intracranial Stenosis. Stroke. 2018:STROKEAHA118020840. https://doi.org/10.1161/ STROKEAHA.118.020840

79. Lin Q, Liu X, Chen B, Tian D, Liu C, Du A, et al. Stroke Imaging Package Study of Intracranial Atherosclerosis (SIPS-ICAS) study group. Design of stroke imaging package study of intracranial atherosclerosis: a multicenter, prospective, cohort study. Ann Transl Med. 2020;8(1):13. https://doi. org/10.21037/atm.2019.11.111

80. Molnar T, Horvath A, Szabo Z, Vamos Z, Dóczi T, Illes Z. Detection of silent cerebral microcirculatory abnormalities in patients with manifest ischemic coronary disease: a perfusion brain MRI study combined with dipyridamole stress. Scand Cardiovasc J. 2020:1-5.

81. Murphy SJ, Lim ST, Kinsella JA, Tierney S, Egan B, Feeley TM, et al. Simultaneous assessment of plaque morphology, cerebral micro-embolic signal status and platelet biomarkers in patients with recently symptomatic and asymptomatic carotid stenosis. J Cereb Blood Flow Metab. 2020;40(11):2201-14. https://doi.org/10.1177/0271678X19884427 
82. Jover E, Rodríguez JM, Bernal A, Arroyo AB, Iniesta JA, Guiú IS, et al. High on-treatment platelet reactivity in patients with ischemic cerebrovascular disease: assessment of prevalence and stability over time using four platelet function tests. Blood Coagul Fibrinolysis. 2014;25(6):604-11. https:// doi.org/10.1097/MBC.0000000000000118

83. Jamison J, Graffy J, Mullis R, Mant J, Sutton S. Barriers to medication adherence for the secondary prevention of stroke: a qualitative interview study in primary care. Br J Gen Pract. 2016;66(649): e568-576. https://doi.org/10.3399/bjgp16X685609

84. Burke JP, Sander S, Shah H, Zarotsky V, Henk H. Impact of persistence with antiplatelet therapy on recurrent ischemic stroke and predictors of nonpersistence among ischemic stroke survivors. Curr Med Res Opin. 2010;26(5):1023-30. https://doi.org/10.1185/03007991003670563 
